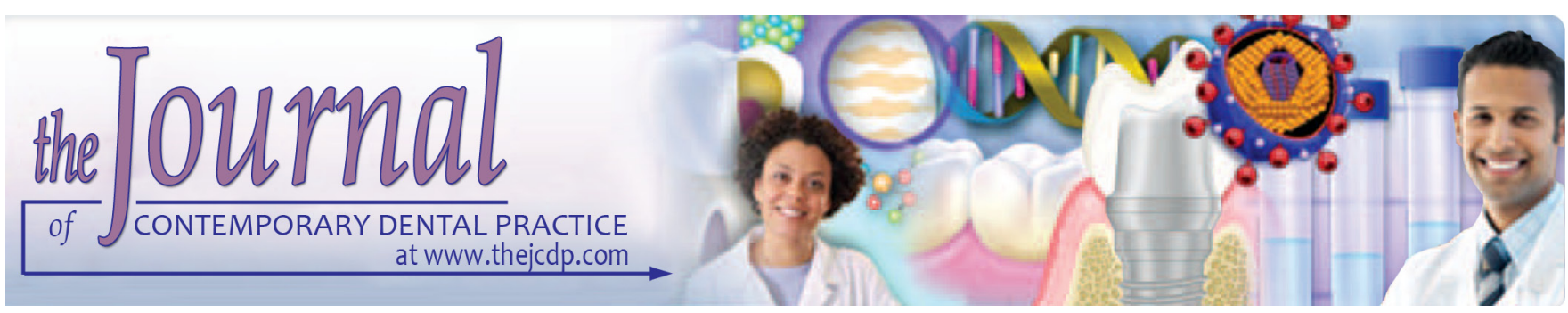

\title{
Comparison of Canal Transportation, Centering Ratio by Cone-beam Computed Tomography after Preparation with Different File Systems
}

${ }^{1}$ Emel Uzunoglu, ${ }^{2}$ Sevinc Aktemur Turker

\begin{abstract}
Aim: One Shape Apical 1 (OSA 1) is a new file for preparing the apical aspect of the root canal after One Shape (OS, Micro Mega, Besançon, France). This study compared apical transportation and centering ratios in curved root canals, which were instrumented with ProTaper Next (PTN, Dentsply Tulsa Dental Specialties, Tulsa, OK) up to size X3 and with OS up to OSA 1.
\end{abstract}

Materials and methods: Forty-eight mesial canals of mandibular molars were assigned into two groups $(n=24)$ with respect to canal length and curvature. Root canals were accessed conventionally and preperation was completed with PTN files up to X3 or with OS up to OSA 1 according to the manufacturer's protocols. Apical transportation was assessed pre- and postinstrumentation using cone-beam computed tomographic (CBCT) scans of $1,2,3,4$, and $5 \mathrm{~mm}$ sections. A Friedman test was performed to assess the significance between file systems.

Results: No significant difference was found between the file systems regarding apical transportation and centering ratio values $(p>0.05)$. Transportation in the mesial direction was greater than the distal transportation for both file systems.

Conclusion: Considering apical transportation and centering ratio in curved canals, two systems provided similar results.

Clinical significance: Preparation up to One Shape Apical 1 or ProTaper Next X3 was shown similar results regarding apical transportation and centering ratio. Both systems were safe to use in curved molar root canals.

\footnotetext{
${ }^{1}$ Department of Endodontics, Faculty of Dentistry, Hacettepe University, Ankara, Turkey

${ }^{2}$ Department of Endodontics, Faculty of Dentistry, Bülent Ecevit University, Zonguldak, Turkey

Corresponding Author: Emel Uzunoglu, Research Assistant Department of Endodontics, Faculty of Dentistry, Hacettepe University, Ankara 06100, Turkey, Phone: +903123052260 e-mail: emel_dt@hotmail.com
}

Keywords: Cone-beam computed tomography, Root canal preparation, Transportation.

How to cite this article: Uzunoglu E, Turker SA. Comparison of Canal Transportation, Centering Ratio by Cone-beam Computed Tomography after Preparation with Different File Systems. J Contemp Dent Pract 2015;16(5):360-365.

\section{Source of support: Nil}

Conflict of interest: None

\section{INTRODUCTION}

The principal aim of root canal shaping is to increase the canal's taper from apical to coronal third and to maintain its original overall shape as well. ${ }^{1}$ Achieving this aim can promote effective irrigation, root canal medication, and, finally, three-dimensional (3D) root canal filling. ${ }^{2}$

Several different methods and devices have been introduced to facilitate appropriate root canal preparation. Nickel-titanium (NiTi) rotary files are used more than 20 years during root canal shaping. Their popularity increase because they reduce treatment duration, operator-patient tiredness and procedural errors related with root canal shaping. Capacity for maintaining the original canal curvature depending to their flexibility is the one of the main advantage of NiTi instruments. ${ }^{3}$

Definition of transportation is the iatrogenically moving of the physiologic terminus to a new position on the external root surface. When the canal is moved from its physiologic location, root structure may become weaker and the risk of perforation, ledge creation, and blockage may increase. ${ }^{4}$ In the case of transportation, root canal filling also may be impaired, resulting in microleakage. ${ }^{4}$ Preparing prominent curved canals with appropriate endodontic instruments, as well preserving their original anatomy will always be difficult, because all devices and preparation methods are capable of transporting and 
changing the original canal shape. ${ }^{5,6}$ The apical third of the root canal is a critical area because it may consist an important amount of microorganisms. ${ }^{7}$ Increased apical enlargement reduces microbial levels, but this can cause to procedural errors, such as root canal transportation and ledge, zip, elbow, and crack formation. ${ }^{8,9}$ Thus, different shaping systems face the challenge of creating centered preparations and minimizing apical root canal transportation.

ProTaper Next (PTN, Dentsply Maillefer, Ballaigues, Switzerland) is a new set of rotary instruments designed with progressive and regressive percentage tapers and an off-centered rectangular cross section that gives the file a snake-like swaggering movement as it advances into the root canal. These instruments are manufactured from M-wire NiTi alloy that is claimed to improve file flexibility and resist cyclic fatigue while retaining cutting efficiency. ${ }^{10,11}$ All instruments are expected to passively follow the canal until the working length is achieved. ${ }^{12}$ There is currently only limited information available regarding the shaping ability of this particular instrument. $^{13-15}$

The One Shape system (OS, Micro-Mega, Besançon, France) is another file system that is made of a conventional austenite $55 \mathrm{NiTi}$ alloy and used in continuous clockwise rotation. These instruments have an innovative design with three different cross-sectional areas over the entire length of the file and have a variable pitch and non-cutting safety tip. ${ }^{16}$ This design is purported to eliminate threading and binding of the instrument during continuous rotation. ${ }^{17}$ Recently, manufactured One Shape Apical (OSA) files are single-use NiTi finishing instruments, which are used after shaping with OS in order to prepare the apical part of the root canal. Two instruments are available: OSA 1 (\#30/.06) and OSA 2 (\#37/.06). One Shape Apical 1 instruments have a 0.06 constant taper only between D0 to D5. Between D6 and D16, it has a 0 taper. The present in vitro study aimed to compare the apical transportation and centering ability of the two aforementioned systems via cone-beam computed tomography (CBCT).

\section{MATERIALS AND METHODS}

Curved mesial roots of mandibular molars, extracted for reasons unrelated to the present study, were used. Twenty-four fully formed human mandibular molars, yielding an average curvature of $20^{\circ}, 18$ that had two different canals in the mesial root that terminated in two individual foramina were used. The distal root of each tooth, together with the coronary portion, was removed with a diamond disk and specimen length was adapted to $13 \mathrm{~mm}$ for standardization. The canals were accessed conventionally using a \#10 K-file (Dentsply Tulsa Dental Specialties, Tulsa, OK, USA) to negotiate to the working length (WL) with sodium hypochlorite ( $\mathrm{NaOCl})$. The WL was decided using a microscope under 10× magnification by advancing a \#10 K-file until it was flush with the apex and then subtracting $0.5 \mathrm{~mm}$ from this length. \#15 K-file (Dentsply Tulsa Dental Specialties) was used for a glide path. Then, with the aid of silicon-based impression material (Speedex, Coltene/Whaledent, Altstätten, Switzerland), specimens were inserted at full length into the plastic mold in parallel position to the walls of mold. A preinstrumentation CBCT scan was then taken. The two balanced groups were randomly assigned: one to be instrumented by the PTN files and the other to be instrumented by the OS and OSA 1 files. All canals were prepared by one operator according to the manufacturer's protocol using an electric motor with torque and speed control. The preparation sequences were as follows: PTN files were used with the sequence ProTaper Universal SX, PTN X1 (\#17/.04), X2 (\#25/.06), X3 (\#30/.07), at a rotational speed of $300 \mathrm{rpm}$ and $200 \mathrm{gcm}$ torque. Each file was used with a brushing motion similar to the ProTaper Universal files. The OS files were used with the sequence OS and OSA 1 at a rotational speed of $400 \mathrm{rpm}$ and $400 \mathrm{gcm}$ torque. In the case of apical resistance, the file was removed and cleaned, and the root canal was irrigated copiously. Canal irrigation consisted of $2 \mathrm{ml}$ of $5.25 \% \mathrm{NaOCl}$ that was used after every file change (PTN) or after every 3 insertions (OS and OSA 1). A \#10 K-file was used after every irrigation cycle to maintain apical patency. Canals were flushed with $3 \mathrm{ml}$ of a $5.25 \% \mathrm{NaOCl}$ solution using a 30-gauge needle (NaviTip, Ultradent, South Jordan, UT, USA) that was inserted as deeply as possible into the canal without binding, after the final file reached to the WL. The final apical file size was 30, for both groups. After the WL was reached in all groups, CBCT imaging of the prepared samples was repeated using the same position and parameters as the preinstrumentation imaging in order to compare pre- and postpreparation images.

\section{СВСТ Analysis}

Specimens were scanned pre- and postinstrumentation with the CBCT device (Carestream 9000 3D, Carestream Dental LLC, USA) with the following settings: $5 \mathrm{~mA}$, $64 \mathrm{Kvp}$, and $76 \mu$ voxel size. Pre- and postinstrumentation measurements were compared to determine the apical transportation and centering ability values (Fig. 1). 


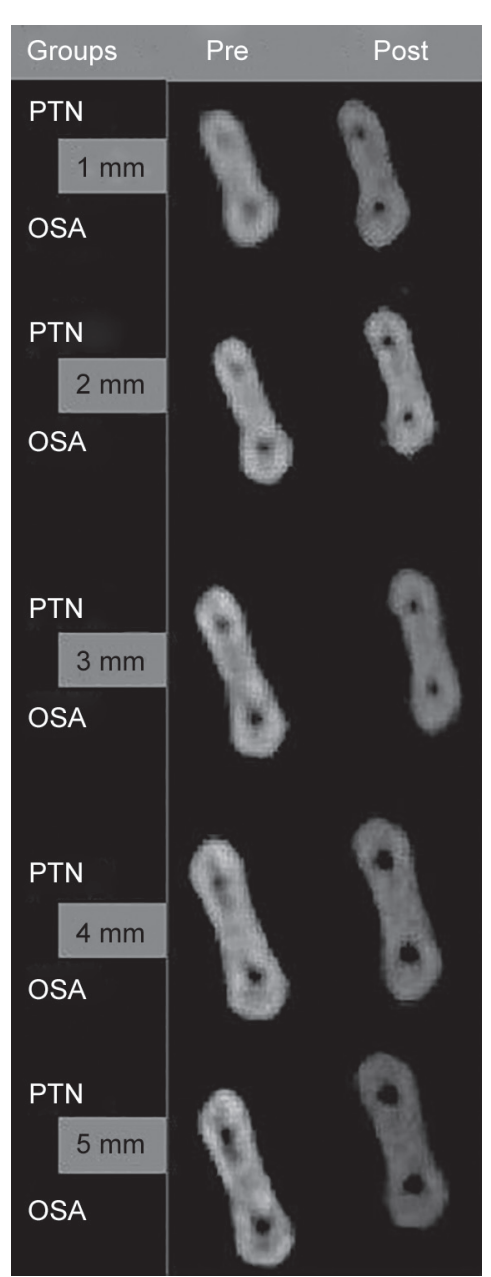

Fig. 1: Cross-sectional CBCT scan images of pre- and postinstrumentation at 1, 2, 3, 4 and $5 \mathrm{~mm}$ sections

Similar formulas were used for calculations as in previous study $1{ }^{19}$ Calculation and comparison of all scans were made at 1-, 2-, 3-, 4- and $5 \mathrm{~mm}$ from the apical foramen using the software NTT Viewer (NTT Software Corporation, Yokohama, Japan) and Adobe Photoshop CS5 (Adobe Systems Inc, San Jose, CA). With regard to CBCT data, the distribution of transportation and centering ratio values was not normal. Data were assessed using the nonparametric Friedman test. The SPSS software (SPSS version 21.0, SPSS, Chicago, IL, USA) was used for the statistical analysis $(\mathrm{p}<0.05$ was considered as statistically significant).

\section{RESULTS}

The centering ratios and transportation values, regardless of direction, from the PTN and OSA 1 groups at five different sections of the canals $(1,2,3,4$ and $5 \mathrm{~mm}$ from apex) are presented in Table 1 . The mean transportation values in the mesial and distal directions are presented in Table 2. The mean transportation was toward the mesial wall for both file systems. No significant differences were detected between the two groups with respect to apical transportation and centering ratios $(\mathrm{p}>0.05)$. There were no significant differences between different levels in PTN and OS groups ( $\mathrm{p}=0.244$ and 0.237 respectively).

\section{DISCUSSION}

Mandibular first molars that had two separate canals ending in two separate foramina in the mesial root were used in the present study. As shown previously, these teeth provide an excellent model for performing a sideby-side comparison of two different shaping systems. ${ }^{20,21}$ In addition, the complicated canal morphology and significant curvatures often make these canals challenging to prepare and will allow for a realistic evaluation of a file system's true capabilities and performance level. ${ }^{20,21}$ Parameters, such as canal length, apical diameter, the angle and the radius of canal curvature, were balanced in order to obtain anatomically comparable groups.

Different methods have been used to assess apical transportation and centering ability. ${ }^{14-16,21-25}$ One of the most used methodology in nowadays is CBCT, since it is reproducible and allows to protection of the specimen. ${ }^{26}$ Several images of the root canal before, during and after instrumentation could be captured via CBCT and they provided detailed information considering root canal anatomy. ${ }^{14,15,25}$ Even though micro-CT is accepted as the gold standard for assessing centering ability of different file systems, CBCT offers many advantages, such as including increased sensitivity and specificity for caries, periodontal and periapical lesions, 3D rendition, patient comfort, geometrically precise images, no intraoral placement of film or sensor and softtissue interpretation. ${ }^{27}$ It is also possible to select smaller field of view, compared to the medical CT scans, which results in high-resolution images, that enhances the accuracy and capacity of diagnosis. ${ }^{28,29}$

In an attempt to obtain effective disinfection during root canal preparation, some authors have emphasized the need to use large-caliber instruments, especially in the apical third. ${ }^{30,31}$ Khademi et a ${ }^{32}$ reported that the amount of apical preparation for the penetration of canal irrigants to the apical third of the canal should be at least \#30. In a previous study, ProTaper Next instruments prepared $25^{\circ}$ to $39^{\circ}$ curved canals up to an apical size of \#30 without significant shaping errors or instrument fracture. ${ }^{33}$ In the present study, the final apical preparation was determined to be size \#30, because larger preparations might result in transportation of the root canal, on the other hand, smaller preparations might not remove all pulpal remnants and infected dentin. ${ }^{24,33,34}$ Dhingra and Parimoo $^{35}$ reported that OS file system removed less residual dentine than Wave One file system. One 


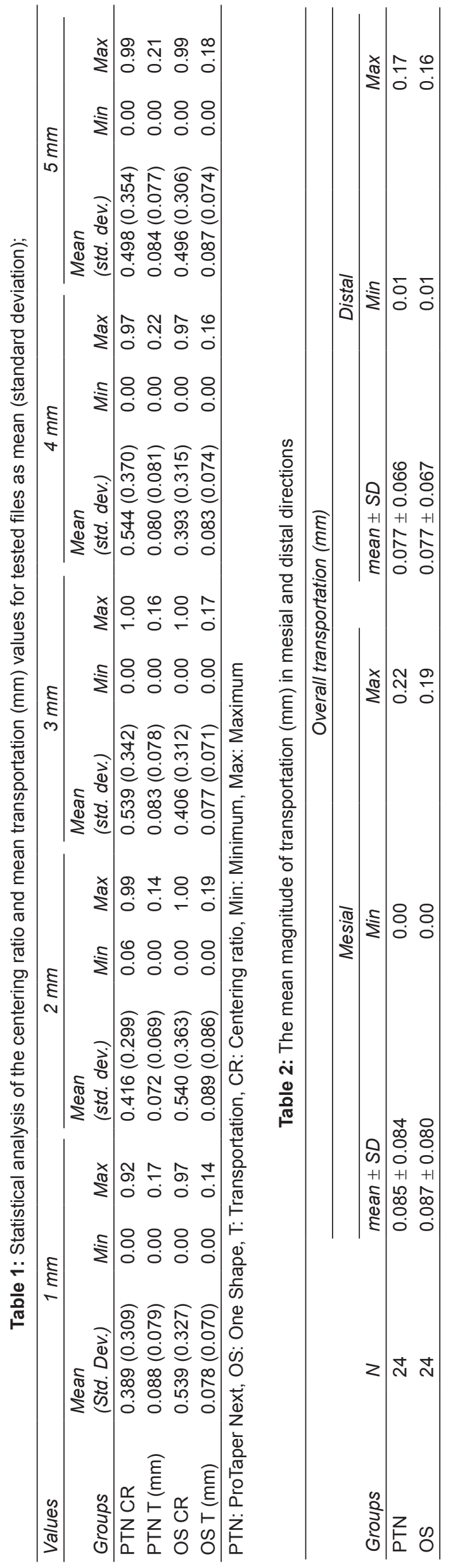


Shape cappical 1 is a new file used to prepare the apical portion of the root canal, and there is no data regarding the shaping capabilities of OSA 1 . The results of this study show that both systems produce similar results regarding canal transportation and centering ability such that the original shape of the curved canal was maintained with minimal changes.

Apical transportation values that are more than $0.3 \mathrm{~mm}$ can endanger the outcome of treatment due to a noticeable decrease in the sealing ability of obturation material. ${ }^{20}$ None of the transportation values measured in this study surpassed this limit. These results are consistent with studies that have used these systems previously. ${ }^{13,14,16,33}$ For example, Bürklein et al $^{16}$ reported that OS properly maintained the original curvature of severely curved canals in extracted teeth. In addition, Capar et al, ${ }_{14}^{14}$ using CBCT imaging, found that PTN X2 and OS maintained root canal curvature equally well and produced similar canal transportation during the preparation of mesial canals of mandibular molars.

\section{CONCLUSION}

According to results of this in vitro study, no significant differences in measures of apical transportation and centering ratio in the preparation of curved mesial canals of mandibular molars were observed between the two systems.

Clinical significance: Preparation up to OSA 1 or PTN X3 was shown similar results regarding apical transportation and centering ratio. Both file systems were safe to use in curved molar root canals.

\section{REFERENCES}

1. Schilder H. Cleaning and shaping the root canal. Dent Clin North Am 1974 Apr;18(2):269-296.

2. Ruddle CJ. In: Cleaning and shaping the root canal system. Cohen S, Bums RC, editors. St Louis: Mosby; 2002.

3. Gluskin AH, Brown DC, Buchanan LS. A reconstructed computerized tomographic comparison of Ni-Ti rotary GT files versus traditional instruments in canals shaped by novice operators. Int Endod J 2001 Sep;34(6):476-484.

4. Franco V, Fabiani C, Taschieri S, Malentacca A, Bortolin M, Del Fabbro M. Investigation on the shaping ability of nickeltitanium files when used with a reciprocating motion. J Endod 2011 Oct;37(10):1398-1401.

5. Freire LG, Gavini G, Branco-Barletta F, Sanches-Cunha R, dos Santos M. Microscopic computerized tomographic evaluation of root canal transportation prepared with twisted or ground nickel-titanium rotary instruments. Oral Surg Oral Med Oral Pathol Oral Radiol Endod 2011 Dec;112(6):143-148.

6. Griffiths IT, Bryant ST, Dummer PM. Canal shapes produced sequentially during instrumentation with Quantec LX rotary nickel-titanium instruments: a study in simulated canals. Int Endod J 2000 Jul;33(4):346-354.
7. Nair PN, Sjogren U, Krey G, Kahnberg KE, Sundqvist G. Intraradicular bacteria and fungi in root-filled, asymptomatic human teeth with therapy-resistant periapical lesions: a longterm light and electron microscopic follow-up study. J Endod 1990 Dec;16(12):580-588.

8. Allison DA, Weber CR, Walton RE. The influence of the method of canal preparation on the quality of apical and coronal obturation. J Endod 1979 Oct;5(10):298-304.

9. Alodeh MH, Doller R, Dummer PM. Shaping of simulated root canals in resin blocks using the step-back technique with K-files manipulated in a simple in/out filling motion. Int Endod J 1989 May;22(3):107-117.

10. Alapati SB, Brantley WA, Iijma M, Clark WA, Kovarik L, Buie C, Liu J, Johnson BW. Metallurgical characterization of a new nickel-titanium wire for rotary endodontic instruments. J Endod 2009 Nov;35(11):1589-1593.

11. Zhou H, Peng B, Zheung YF. An overview of the mechanical properties of nickel-titanium endodontic instruments. Endod Topics 2013 Sep;29(1):42-54.

12. ProTaper Next: directions for use. Available at: http:/www. protapernext.com/benefits- concept.html. Accessed on: 2014 October 10.

13. Bürklein S, Mathey D, Schäfer E. Shaping ability of ProTaper NEXT and BT-RaCe nickel-titanium instruments in severely curved root canals. Int Endod J 2014; doi: 10.1111/iej.12375. [Epub ahead of print].

14. Capar ID, Ertas H, Ok E, Arslan H, Ertas ET. Comparative Study of Different Novel Nickel-Titanium Rotary Systems for Root Canal Preparation in Severely Curved Root Canals. J Endod 2014 Jun;40(6):852-856.

15. Elnaghy AM, Elsaka SE. Evaluation of Root Canal Transportation, Centering Ratio, and Remaining Dentin Thickness Associated with ProTaper Next Instruments with and without Glide Path. J Endod 2014 Dec;40(12):2053-2056.

16. Bürklein S, Benten S, Schäfer E. Shaping ability of different single-file systems in severely curved root canals of extracted teeth. Int Endod J 2013 Jun;46(6):590-597.

17. Bürklein S, Hiller C, Huda M, Schäfer E. Shaping ability and cleaning effectiveness of $\mathrm{M}$ two versus coated and uncoated EasyShape instruments in severely curved root canals of extracted teeth. Int Endod J 2011 May;44(5):447-457.

18. Schneider SW. A comparison of canal preparations in straight and curved root canals. Oral Surg Oral Med Oral Pathol 1971 Aug;32(2):271-275.

19. Gambill JM, Alder M, del Rio CE. Comparison of nickeltitanium and stainless steel hand-file instrumentation using computed tomography. J Endod 1996 Jul;22(7):369-375.

20. Garcia M, Duran-Sindreu F, Mercadé M, Bueno R, Roig M. A comparison of apical transportation between ProFile and RaCe rotary instruments. J Endod 2012 Jul;38(7):990-992.

21. Junaid A, Freire LG, da Silveira Bueno CE, Mello I, Cunha RS. Influence of single-file endodontics on apical transportation in curved root canals: an ex vivo micro-computed tomographic study. J Endod 2014 May;40(5):717-720.

22. Bramante CM, Berbert A, Borges RP. A methodology for evaluation of root canal instrumentation. J Endod 1987 May; 13(5):243-245.

23. Kuttler S, Garala M, Perez R, Dorn SO. The endodontic cube: a system designed for evaluation of root canal anatomy and canal preparation. J Endod 2001 Aug;27(8):533-536. 
24. Ceyhanli KT, Erdilek N, Tatar I, Cetintav B. Comparative micro-computed tomography evaluation of apical root canal transportation with the use of ProTaper, RaCe and Safesider systems in human teeth. Aust Endod J 2014 Apr;40(1):12-16.

25. Hartmann MS, Barletta FB, Camargo-Fontanella VR, Vanni JR. Canal transportation after root canal instrumentation: A comparative study with computed tomography. J Endod 2007 Aug;33(8):962-965.

26. Peck MT. Interpretation basics of cone beam computed tomography. In: Gonzalez SM, editor. Int J Contemp Dent Med Rev 2015;2015: Article ID 130115. DOI: 10.15713/ins.ijcdmr.34.

27. Durack C, Patel S. Cone beam computed tomography in endodontics. Braz Dent J 2012;23(3):179-191.

28. Ludlow JB, Davies-Ludlow LE, Brooks SL, Howerton WB. Dosimetry of 3 CBCT devices for oral and maxillofacial radiology: CB Mercuray, NewTom 3G and i-CAT. Dentomaxillofac Radiol 2006 Jul;35(4):219-226.

29. Hatcher DC. Operational principles for cone-beam computed tomography. J Am Dent Assoc 2010 Oct;141(Suppl 3):3S-6S.
30. Mickel AK, Chogle S, Liddle J, Huffaker K, Jones JJ. The role of apical size determination and enlargement in the reduction of intracanal bacteria. J Endod 2007 Jan;33(1):21-23.

31. Wu MK, Barkis D, Roris A, Wesselink PR. Does the first file to bind correspond to the diameter of the canal in the apical region? Int Endod J 2002 Mar;35(3):264-267.

32. Khademi A, Yazdizadeh M, Feizianfard M. Determination of the minimum instrumentation size for penetration of irrigants to the apical third of root canal systems. J Endod 2006 May;32(5):417-420.

33. Saber SEDM, Nagy MM, Schäfer E. Comparative evaluation of the shaping ability of ProTaper Next, iRaCe and Hyflex CM rotary NiTi files in severely curved root canals. Int Endod J 2015 Feb;48(2):131-136.

34. Schäfer E, Dammaschke T. Development and sequelae of canal transportation. Endod Topics 2006 Nov;15(1):75-90.

35. Dhingra A, Parimoo D. Evaluation of remaining dentine thickness using wave one and one shape file system with cone beam computed tomography. Int J Contemp Dent Med Rev 2014;2014: Article ID 071114, doi: 10.157139 ins.ijcdmr.23. 